\title{
ESTUDO DO PRÉ-TRATAMENTO DE BAGAÇO DE CAJU UTILIZANDO LÍQUIDO IÔNICO
}

\author{
C. L. B. REIS ${ }^{1}$, J. A. $\operatorname{COSTA}^{1}$, C. B. S. MATIAS ${ }^{1}$, A. K. N. FELIX $^{1}$, R. S. SANTIAGO-AGUIAR ${ }^{1}$ e \\ M. V. ROCHA ${ }^{1}$ \\ ${ }^{1}$ Universidade Federal do Ceará, Departamento de Engenharia Química \\ E-mail para contato: carlaluzia2910@hotmail.com; valderez.rocha@ufc.br
}

\begin{abstract}
RESUMO - Estudou-se o pré-tratamento do bagaço de caju (BC), um resíduo lignocelulósico da agroindústria do caju, utilizando líquido iônico (LI). Inicialmente, o LI foi sintetizado por reação de ácido acético e monoetanolamina (acetato de 2hidroxietanolamina), nomeado 2-HEAA. O pré-tratamento consistiu na extração da lignina da fração rica em carboidratos por meio da adição de $\mathrm{NaOH} 0,1 \mathrm{M}$ após a dissolução do BC no LI e após separou-se a hemicelulose da fração rica em lignina. $\mathrm{O}$ tempo de dissolução do BC no LI foi avaliado. A caracterização das frações obtidas foi conduzida utilizando FTIR. Para avaliar a eficiência dos pré-tratamentos e verificar a apliBCilidade das frações obtidas ricas em carboidratos, submeteu-se essas frações à hidrólise enzimática usando Cellulase $1.5 \mathrm{~L}$, com carga de $30 \mathrm{FPU} / \mathrm{mL}$ a $45^{\circ} \mathrm{C}, 150 \mathrm{rpm}$ por 72h. Os métodos desenvolvidos permitiram a separação da fração de carboidratos da lignina e as frações celulósicas mostraram uma alta digestibilidade.
\end{abstract}

\section{INTRODUÇÃO}

Materiais lignocelulósicos representam uma fonte sustentável de biomassa para a transformação em biocombustíveis e produtos de base biológica, sendo essencialmente representados por madeira, gramíneas, resíduos agrícolas e florestais, resíduos sólidos urbanos e resíduos da indústria de alimentos (Lopes et al., 2013). Pode-se citar como exemplo, o bagaço de caju, um resíduo da produção do suco do pedúnculo de caju na região Nordeste do Brasil sendo produzidos $15 \% \mathrm{~m} / \mathrm{m}$ de bagaço de caju nesse processamento, que não apresenta nenhum valor comercial ou é aproveitado.

O bagaço de caju (como outras biomassas) é composto principalmente de celulose, hemicelulose e lignina, que formam uma estrutura complexa e intrincada, sendo essas características uma das maiores dificuldades para o aproveitamento dos resíduos lignocelulósicos por biotransformação, tanto microbiana e enzimática, o que limita seu uso e evita conversão economicamente viáveis em produtos de valor agregado (Correia et al., 2013). Por isso vários tipos de pré-tratamentos são estudados para modificar essa estrutura (Rodrigues et al., 2011; Correia et al., 2013; Rocha et al., 2014) e entre as tecnologias alternativas de pré-tratamento, uma que está sendo amplamente estudada é focada na aplicação líquido iônico. 


\section{9 a 22 de outubro de 2014 \\ Florianópolis/SC}

Os líquidos iónicos (ILS) têm apresentado como um novo tipo de solvente não aquoso para biocatálise, principalmente devido às suas propriedades físicas únicas e ajustáveis. Líquidos iônicos são sais orgânicos de alto peso molecular que são líquidos a temperatura ambiente. Estas substâncias têm recebido considerável atenção como solventes ecologicamente corretos, já que não possuem pressão de vapor mensurável e, portanto, não apresentam emissões tóxicas ou poluentes como os solventes orgânicos tradicionais (Santiago-Aguiar, 2009). Stracke (2008) apresentou outras características dos líquidos iônicos (LIs) como, estabilidade térmicas e químicas mais favoráveis que os solventes usuais, são usualmente líquidos numa ampla faixa de temperatura (aproximadamente a ambiente), apresentam viscosidade suficientemente baixa $\left(<800 \mathrm{cP}\right.$ a $\left.20{ }^{\circ} \mathrm{C}\right)$, são solventes tipicamente não coordenantes, podendo dissolver uma gama de compostos orgânicos e inorgânicos e com diferentes solubilidades.

Neste contexto, o presente trabalho teve como objetivo estudar o pré-tratamento do bagaço de caju (BC), um resíduo lignocelulósico da agroindústria do caju, utilizando um líquido iônico prótico (LI). Inicialmente, o LI foi sintetizado por reação de ácido acético e monoetanolamina, obtendo acetato de 2-hidroxietanolamina, nomeado 2-HEAA. Além disso, a fim de verificar o potencial de apliBCilidade das frações ricas em carboidratos obtidas, e para avaliar a eficácia do pré-tratamento, a fração de celulose resultante do tratamento com 2-HEAA foi submetida à hidrólise enzimática.

\section{MATERIAL E MÉTODOS}

\subsection{Material lignocelulósico}

Utilizou-se neste estudo como material lignocelulósico o bagaço de caju (BC), que foi gentilmente cedido pela Indústria de Processamento de Sucos Jandaia no Ceará, Brasil. Inicialmente o bagaço de caju foi lavado três vezes com água e seco em uma estufa (Tecnal, Modelo TE-394/1) com renovação de ar a $60{ }^{\circ} \mathrm{C}$ por $24 \mathrm{~h}$. Em seguida, o BC foi triturado, peneirado e selecionado as partículas com diâmetro de $0,25-0,84 \mathrm{~mm}$ para a realização dos experimentos. BC foi estocado até seu uso a temperatura ambiente (aproximadamente $28^{\circ} \mathrm{C}$ ).

\subsection{Síntese do Líquido Iônico}

A síntese do líquido iônico se deu a partir de uma reação de neutralização ácido-base utilizando como reagentes o ácido acético e monoetanolamina, de acordo com metodologia descrita por Álvarez (2010). A monoetanolamina foi adicionada em um balão de três bocas, equipado com um condensador de refluxo, um funil contendo o ácido acético e um termômetro. $\mathrm{O}$ ácido acético foi adicionado gota a gota à amina e o sistema foi mantido em agitação a $35{ }^{\circ} \mathrm{C}$ por $24 \mathrm{~h}$. Após a preparação do líquido iônico determinou-se a densidade e a velocidade do som a 297,15 K, usando um densímetro Anton Paar DSA 5000. 


\section{9 a 22 de outubro de 2014 \\ Florianópolis/SC}

\subsection{Pré-tratamento do Bagaço de Caju com Líquido Iônico}

A metodologia do pré-tratamento do bagaço de caju utilizando a dissolução no líquido iônico 2HEAA foi adaptada do estudo realizado por Lopes et al. (2013) no fracionamento de palha de trigo utilizando 1-etil-3-metilimidazolium acetato ([emim] $\left.\left[\mathrm{CH}_{3} \mathrm{COO}\right]\right)$ como líquido iônico. O prétratamento foi realizado em seis procedimentos descritos a seguir.

Procedimento 1: Em um reator acoplado a um banho ultra-termostático (Tecnal, TE-2005) adicionou-se 1 grama de bagaço de caju in natura e $5 \mathrm{~g}$ de líquido iônico (2-HEAA) e conduziu-se o pré-tratamento a $80{ }^{\circ} \mathrm{C}$ e $150 \mathrm{rpm}$ por $24 \mathrm{~h}$. Após, adicionou-se lentamente $160 \mathrm{~mL}$ de $\mathrm{NaOH} 0,1 \mathrm{M}$ sob agitação de $150 \mathrm{rpm}$, logo após foi separado o líquido I do sólido I por filtração. Esse sólido rico em carboidratos foi lavado até ajustar o $\mathrm{pH}$ a 7,0. O sólido foi colocado em uma estufa com circulação a $60^{\circ} \mathrm{C}$ por $16 \mathrm{~h}$.

Procedimento 2: Este procedimento se baseia em recuperar a hemicelulose do filtrado I. Esse filtrado foi aquecido a $90{ }^{\circ} \mathrm{C}$, até diminuir significativamente o volume de água, posteriormente foi ajustado o pH da solução para $6,8 \mathrm{com} \mathrm{HCl} 4 \mathrm{M}$ e $1 \mathrm{M}$. Após, o volume da solução foi medido e acrescido álcool $96 \%$ na proporção de 3:1 e então filtrado a vácuo, obtendo o filtrado II e fração rica em hemicelulose. Essa fração foi colocada na estufa a $60^{\circ} \mathrm{C}$ por $16 \mathrm{~h}$ para secagem.

Procedimento 3: Nessa parte foi realizada a extração da lignina do filtrado II. Inicialmente o filtrado II foi aquecido a $90{ }^{\circ} \mathrm{C}$, até diminuir significativamente o volume de água, $\log$ o após foi ajustado o $\mathrm{pH}$ da solução para $2,0 \mathrm{com} \mathrm{HCl} 4 \mathrm{M}$ e $1 \mathrm{M}$. Posteriormente, aqueceu-se a $70{ }^{\circ} \mathrm{C}$ no reator acoplado ao banho ultra-termostático (Tecnal, TE-2005) por $30 \mathrm{~min}$. Posteriormente filtrou-se, obtendo-se uma fração rica em lignina e o filtrado III.

Procedimento 4: A fração rica em celulose é obtida a partir do solido I, na qual foi acrescida $\mathrm{NaOH} 3 \%$ na proporção de $1: 25 \mathrm{~m} / \mathrm{v}$ a $50{ }^{\circ} \mathrm{C}, 150 \mathrm{rpm}$ por $45 \mathrm{~min}$. Posteriormente foi filtrado a vácuo, separando a celulose do filtrado IV.

Procedimento 5: Afim de obter a fração rica em hemicelulose do filtrado IV, o procedimento 2 foi realizado no filtrado IV, obtendo assim uma fração rica em hemicelulose e o filtrado V.

Procedimento 6: Ainda foi possível extrair lignina do filtrado V, sendo repetido o procedimento 3, obtendo como produto lignina e filtrado VI.

Para avaliar a influência do tempo inicial de dissolução do BC no líquido iônico, realizou-se outro ensaio com o tempo reacional de $6 \mathrm{~h}$ (Procedimento 1) e o os demais procedimento conduzidos sem alteração. Também foi realizado um balanço de massa durante todo o experimento para avaliar as perdas. Esses experimentos foram conduzidos em triplicata e os resultados apresentados como média.

A Figura 1 apresenta um fluxograma do experimento realizado para melhor entendimento do processo realizado. 


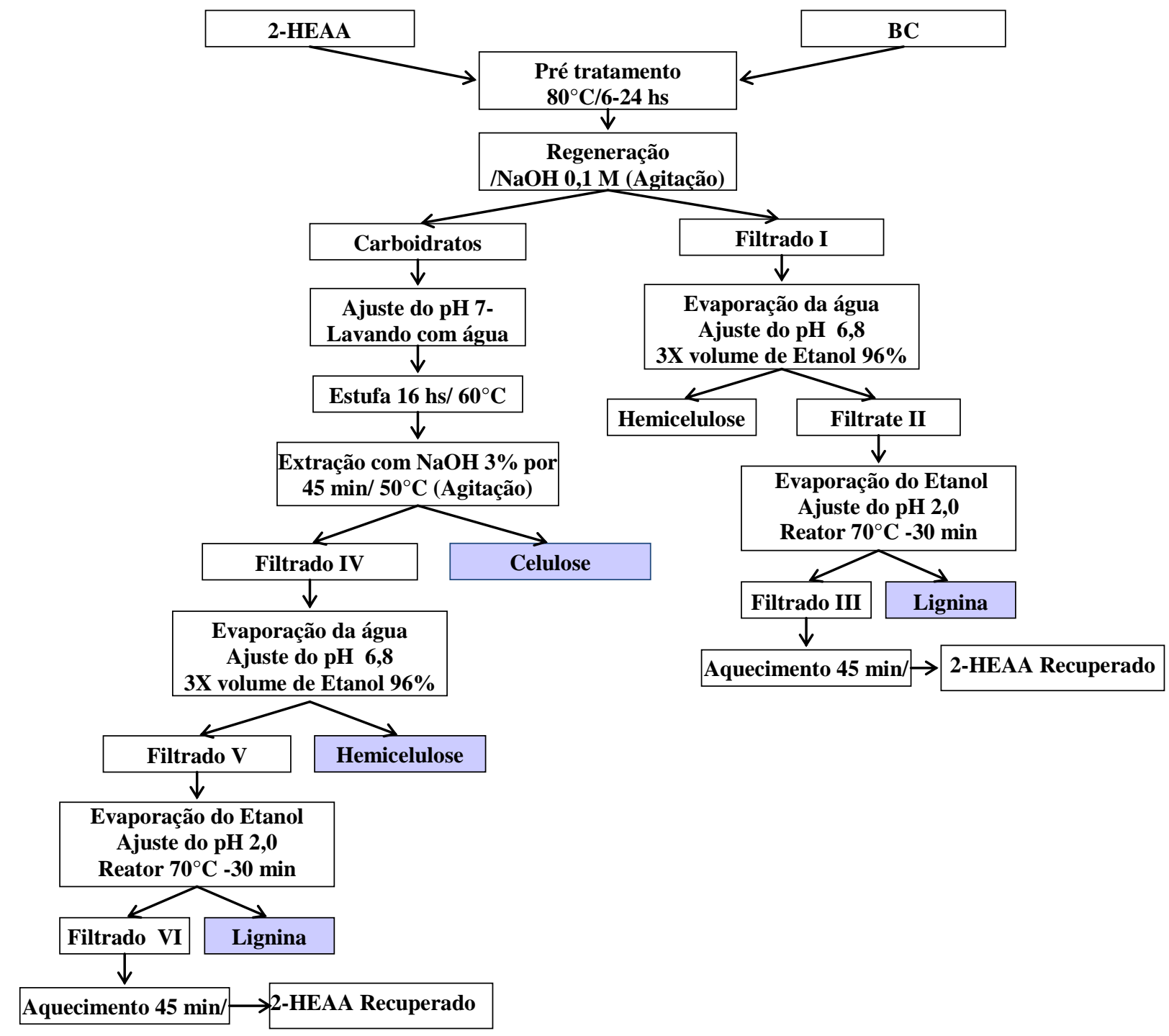

Figura 1 - Fluxograma do pré-tratamento do bagaço de caju in natura utilizando líquido iônico (2HEAA). Os quadrados com preenchimento azul representam as frações celulósicas, hemicelulósica e lignina obtidas durante o procedimento.

\subsection{Hidrólise Enzimática da Fração Rica em Celulose}

A hidrólise enzimática foi realizada segundo a metodologia escrita no protocolo da NREL/TP510-42629 (Selig et al., 2008) com algumas modificações. A hidrólise foi realizada em frascos Erlemneyers de $50 \mathrm{~mL}$ com volume reacional de $10 \mathrm{~mL}$ e $0,1 \mathrm{~g}$ da fração rica em celulose. A carga enzimática utilizada foi $30 \mathrm{FPU} / \mathrm{g}_{\text {celulose }}$ de celulase Celluclast 1.5L (SIGMA) com atividade de 128,94 FPU.mL ${ }^{-1}$. A hidrólise foi conduzida a $45{ }^{\circ} \mathrm{C}, 150 \mathrm{rpm}$ por $72 \mathrm{~h}$. Em intervalos pré-determinados foram retiradas alíquotas da mistura reacional, filtradas e analisadas por cromatografia líquida segundo a metodologia descrita por Correia et al. (2013), para determinação de glicose, xilose e 

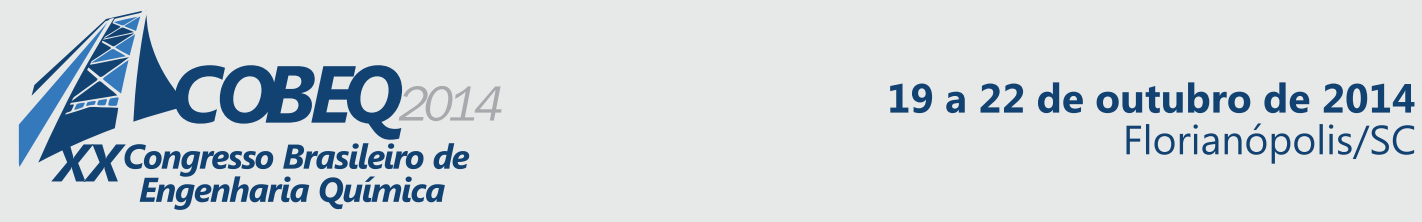

arabinose. Após, determinou-se o rendimento de glicose em mg glicose/g de fração rica em celulose.

\subsection{Caracterização das frações obtidas}

Para a determinação das concentrações existentes de celulose, hemicelulose e lignina nas frações ricas em celulose e hemicelulose obtida no pré-tratamento, foi utilizado a técnica de Infravermelho com Transformada de Fourier. Para a análise quantitativa, a mesma massa das frações foram misturados com $50 \mathrm{mg}$ de $\mathrm{KBr}$ e moído num almofariz, até obter uma mistura homogênea, após foram prensadas para preparação das pastilhas. Esta metodologia de preparação de amostras foi padronizada para as frações visando minimizar os erros experimentais associados à preparação de amostras para FTIR. Todos os espectros foram obtidos com um espectrômetro FTIR Varian (Modelo 620-IR), na região de comprimento de onda de 4000-400 $\mathrm{cm}^{-1}$ com uma resolução de $4 \mathrm{~cm}^{-1} \mathrm{e}$ registrados como absorbância.

\section{RESULTADOS}

\subsection{Pré-tratamento do Bagaço de Caju}

O líquido iônico acetato de 2-hidroxietanolamina (2-HEAA) apresentou uma densidade de $1,1524 \mathrm{~g} . \mathrm{cm}^{-3}$ e uma velocidade do som de $1884,99 \mathrm{~m} \cdot \mathrm{s}^{-1}$ e observou-se uma dissolução do BC em 2HEAA durante o pré-tratamento, principalmente no tempo de $24 \mathrm{~h}$.

A espectroscopia de infravermelho com transformada de Fourier (FTIR) foi selecionada para caracterizar todas as amostras de sólidos recuperados a partir do bagaço de caju (dados não apresentados). Inicialmente, avaliou-se o espectro do BC in natura e observaram-se bandas de absorção em 1376, 1161, 1107, 1049 e $898 \mathrm{~cm}^{-1}$, atribuídas a carboidratos presente na biomassa, uma banda em $1376 \mathrm{~cm}^{-1}$ correspondente a um desvio da ligação C-H em celulose, uma banda referente à ligação C-O foi observada em $1161 \mathrm{~cm}^{-1}$ e uma banda a $898 \mathrm{~cm}^{-1}$ correspondente à vibração das ligações $\beta$-glicosídica do estiramento $\mathrm{C}$ - $\mathrm{H}$, com uma contribuição da vibração do anel presente em moléculas de hexoses e pentoses, característico de ligações glicosídicas em carboidratos. As bandas características da cadeia de lignina presente no espectro do BC foram em 1508, 1458 e $1420 \mathrm{~cm}^{-1} \mathrm{e}$ estão associados com vibrações da cadeia principal de aromáticos como, também, bandas a 1508 e $1458 \mathrm{~cm}^{-1}$, atribuídas às vibrações $\mathrm{C}=\mathrm{O}$ e deformações $\mathrm{C}-\mathrm{H}\left(\mathrm{CH}\right.$ e $\left.\mathrm{CH}_{2}\right)$ em anéis de fenol, respectivamente.

Com esta analise obteve-se a caracterização do BC in natura que apresentou uma composição de $30,6 \% \mathrm{~m} / \mathrm{m}$ de carboidratos (celulose + hemicelulose), $35,2 \% \mathrm{~m} / \mathrm{m}$ de lignina e $34,2 \% \mathrm{~m} / \mathrm{m}$ de outros componentes como, gorduras, ceras, cinzas e pectinas. Essa composição determinada por análise de FTIR, foi semelhante à citada por Correia et al. (2013) utilizando hidrólise ácida.

Através das análises de FTIR, observou-se que os materiais regenerados são essencialmente compostos por carboidratos, devido extração da lignina no processo usando o 2-HEAA. As bandas a 1376 e $1161 \mathrm{~cm}^{-1}$ podem ser observadas no espectro das frações ricas em celulose e o aparecimento 
de novas bandas a 2900,1066, 1046 e $900 \mathrm{~cm}^{-1}$, característica de carboidratos, foram detectadas. O pico de absorção a $1066 \mathrm{~cm}^{-1}$ é um efeito da ligação éter C-O-C das cadeias de pentoses e hexoses, unidade que compõem a molécula de celulose e hemicelulose. $\mathrm{O}$ pico em $1046 \mathrm{~cm}^{-1}$ é atribuído a absorções explicitamente da hemicelulose, alongamento $\mathrm{C}-\mathrm{O}$ em ligações $\mathrm{C}-\mathrm{O}-\mathrm{C}$. Cadeias de arabinose são representadas pelo pico de absorção a $996 \mathrm{~cm}^{-1}$. As absorbâncias que representam lignina, bandas em 1654, 1508 e $1458 \mathrm{~cm}^{-1}$, mostraram uma ligeira diminuição, demonstrando um menor teor de lignina em relação ao BC in natura.

Os espectros das frações ricas em hemicelulose são significativamente diferentes comparados aos espectros das frações ricas em celulose. Novas bandas de absorção em 993, 1043, 1080, 1251 e $1388 \mathrm{~cm}^{-1}$, característica de componentes da cadeia de hemicelulose foram encontradas. Bandas em 993 e $1.163 \mathrm{~cm}^{-1}$ indicam a presença de cadeias laterais de arabinose. A banda de absorção forte em $1043 \mathrm{~cm}^{-1}$ está associada com a ligação glicosídica C-O-C em xilanas.

As Figuras 2A e 2B apresentam os balanços de massa para as frações obtidas durante o prétratamento por 6 e $24 \mathrm{~h}$, respectivamente.

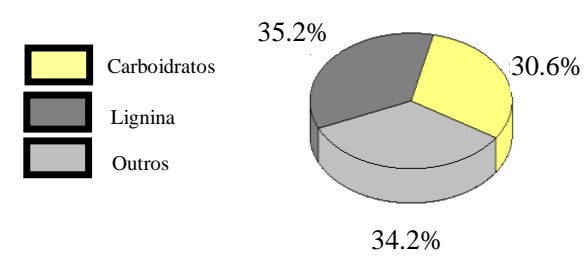

Bagaço de caju in natura

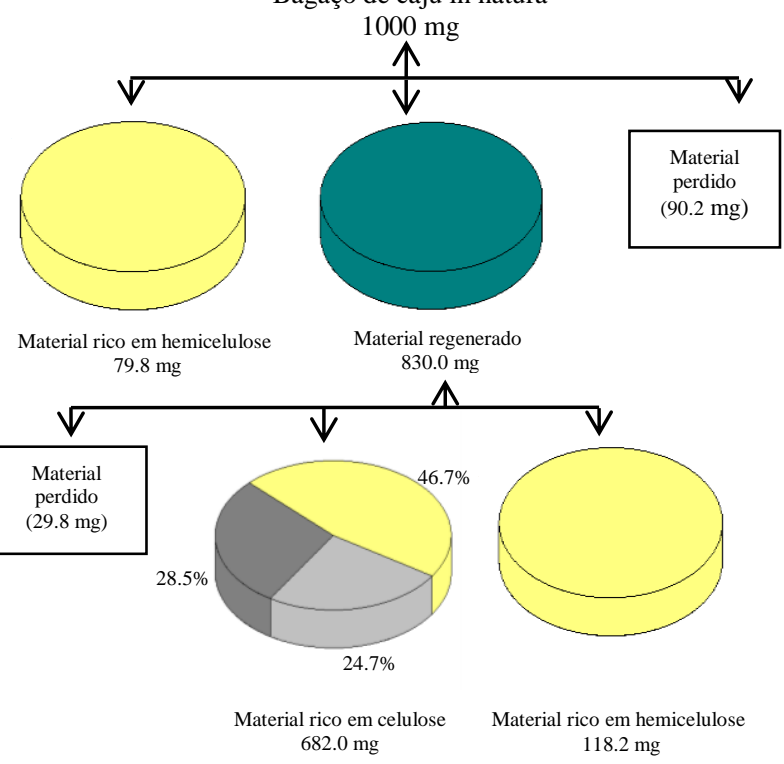

(A)

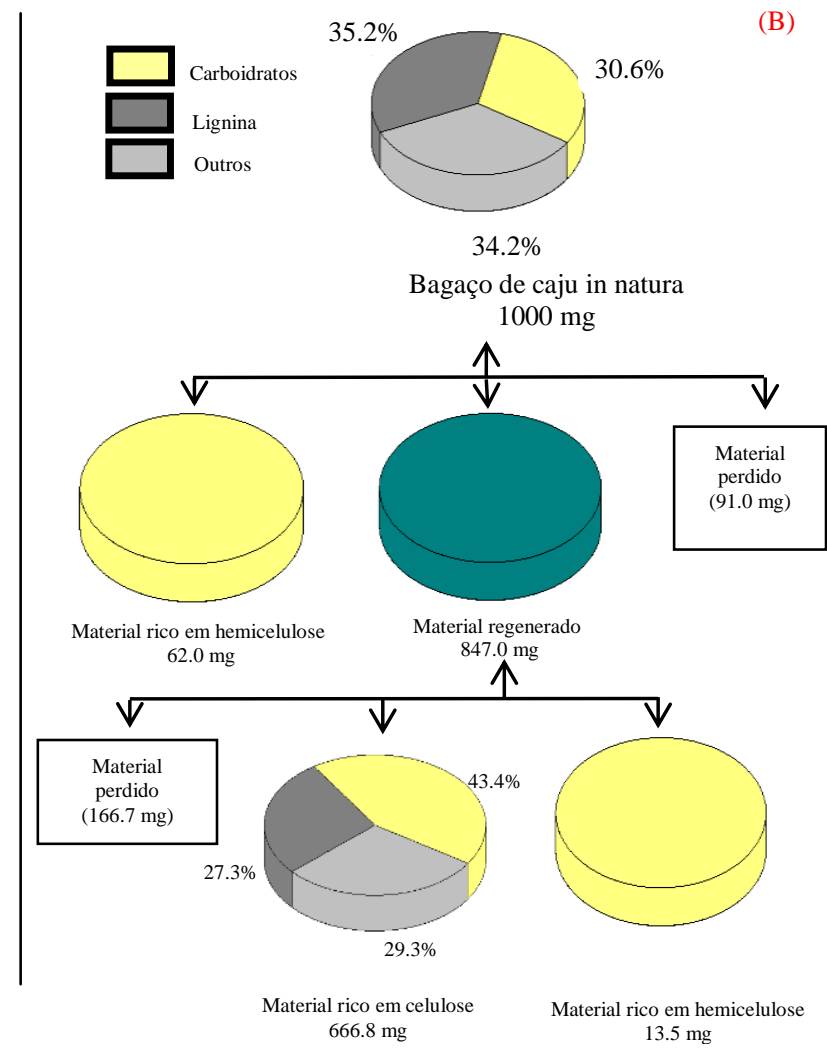

Figura 02 - Balanço de massa das frações obtidas durante o pré-tratamento do bagaço de caju com liquido iônico 2-HEAA conduzido por 6 horas (A) e 24 horas (B).

A menor perda de material (12\%) ocorreu no processo com 6 horas de dissolução do BC no 


\section{9 a 22 de outubro de 2014 \\ Florianópolis/SC}

líquido iônico, sendo obtido $669,8 \mathrm{mg}$ da fração rica em celulose composta por 46,5\% de carboidratos, $28,5 \%$ de lignina e $24,7 \%$ de outros componentes, e $118 \mathrm{mg}$ da fração rica em hemicelulose. Os rendimentos das frações ricas em celulose foram semelhantes para os dois processos (6 e $24 \mathrm{~h}$ ), no entanto, a porcentagem de carboidratos foi superior no pré-tratamento realizado por $6 \mathrm{~h}$ e o no processo conduzido por $24 \mathrm{~h}$ houve uma perda de $25,7 \%$ de material. O pré-tratamento com 2 HEAA proporcionou uma remoção de $44,8 \%$ e 48,3\% de lignina para os processos conduzidos por 6 e $24 \mathrm{~h}$, respectivamente.

\subsection{Hidrólise Enzimática}

A Figura 3 apresenta o rendimento de glicose obtido na hidrólise enzimática do BC in natura e das frações ricas em celulose obtidas com 6 e 24 h de pré-tratamento. O rendimento obtido com o BC in natura foi $18,98 \mathrm{mg}_{\text {glicose }} / \mathrm{g}_{\text {fração rica em carboidratos, valor bem inferior ao obtido com as frações ricas em }}$ carboidratos. Esse resultado se deve principalmente ao alto teor de lignina na biomassa, sendo um fator que limita a hidrólise enzimática, devido a várias razões como: a lignina atua como uma barreira física que limita a acessibilidade das enzimas celulases e hemicelulases ao substrato; ocorre adsorção das celulases na lignina (Qi et al, 2011) e a lignina também pode inibir diretamente as enzimas hidrolíticas (Van Dyk e Pletscke, 2012). O maior rendimento de glicose $\left(464,4 \pm 23 \mathrm{mg}_{\text {glicose }} / \mathrm{g}_{\text {fração rica }}\right.$ em carboidratos) foi obtido no pré-tratamento realizado por 6 horas a $80{ }^{\circ} \mathrm{C}$ e $150 \mathrm{rpm}$ e $344,9 \pm 23 \mathrm{mg}$ de glicose/g de fração rica em carboidratos para o processo de 24 horas.

As frações obtidas nesse estudo podem ser utilizadas em diferentes processos. Nos processos de valorização de biomassa lignocelulósica, celulose e hemicelulose são principalmente hidrolisadas a monossacarídeos, subsequentemente, convertidos em álcoois (etanol, butanol), hidrogênio ou metano por processos de fermentação, em plataformas bioquímicas. Além de biocombustível e energia, a celulose pode ser utilizada para produzir produtos mais caros, tais como hidroximetilfurfural (HMF) (Zakrzewska et al., 2011). A hemicelulose também pode servir como matéria-prima para produtos com valor agregado, tais como combustíveis e xilitol (Girio et al., 2010). A lignina é utilizada não somente para a produção de calor ou combustível, mas também para a fabricação de diversos produtos, tais como ligantes, dispersantes, emulsionantes e sequestrantes, poliuretano e poliésteres (Berlin e Balakshin, 2014).

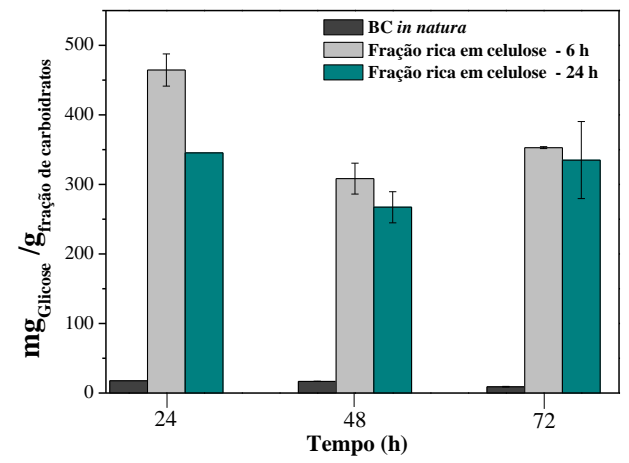

Figura 03 - Rendimento de glicose obtido da hidrólise enzimática do bagaço de caju in natura e as frações ricas em celulose obtidas após 6 e 24 h de pré-tratamento usando líquido iônico (2-HEAA). 


\section{9 a 22 de outubro de 2014 \\ Florianópolis/SC}

\section{CONCLUSÃO}

O pré-tratamento do bagaço de caju usando o líquido iônico sintetizado 2-HEAA apresentou bastante promissor. $\mathrm{O}$ método desenvolvido permitiu obter frações sólidas ricas em carboidratos, com remoção e recuperação da lignina. A hidrólise enzimática da fração rica em celulose em carboidratos resultou em $66 \%$ de liberação de glicose, que poderá ser utilizada na produção de etanol, por exemplo.

\section{REFERÊNCIA}

ÁLVAREZ, V. H. A. Termodinâmica e Aplicações de Líquidos Iônicos. Tese (Doutorado em Engenharia Química) Faculdade de Engenharia Química, Universidade Estadual de Campinas, Campinas, 382 f. 2010.

BERLIN, A. BALAKSHIN. M. Chapter 18 - Industrial Lignins: Analysis, Properties, and Applications. Bioenergy Research: Advances and Applications, p. 315-336, 2014.

CORREIA, J.A.C.; GONÇALVES, L.R.B.; ROCHA, M.V.P. Alkaline Hydrogen Peroxide Pretreatment of Cashew Apple Bagasse for Ethanol Production: Study of Parameters. Bioresour. Technol., p. 249-256, 2013.

GIRIO, F.; FONSECA, C.; CARVALHEIRO, F.; DUARTE, L.; MARQUES, S.; BOGEL-ŁUKASIK, R. Hemicelluloses for fuel ethanol: A review. Bioresour. Technol., v. 101 (13), p. 4775-4800, 2010.

LOPES, A. M. C.; JOÃO, K. G.; RUBIK, D.; BOGEL-LUKASIK, E.; ANDREAUS, J.; DUARTE, L.C.; BOGELLUKASIK, R. Pretreatment of lignocellulosic biomass using ionic liquids: Wheat straw fractionation. Bioresource Technology, v.142, 198-208, 2013.

QI B, CHEN X, WAN Y. Pretreatment of wheat straw by nonionic surfactant-assisted dilute acid for enhancing enzymatic hydrolysis and ethanol production. Bioresour. Technol. v. 101, p. 4875-83, 2010.

ROCHA, M.V.P; RODRIGUES, T.H.S; ALBUQUERQUE, T.L.; GONÇALVES, L.R.G; MACEDO, G.R. Evaluation of dilute acid pretreatment on cashew apple bagasse for ethanol and xylitol production. Chem. Eng. J., v. 243, p. 234-243, 2014.

RODRIGUES, T.H.S.; ROCHA, M.V.P.; MACEDO, G.R.; GONÇALVES, L.R.B. Ethanol Production from Cashew Apple Bagasse: Improvement of Enzymatic Hydrolysis by Microwave-Assisted Alkali Pretreatment. Appl. Biochem. Biotechnol. v. 164, p.929-943, 2011.

SANTIAGO-AGUIAR, R. S. Modelagem termodinâmica de equilíbrio liquido-liquido em sistemas envolvendo líquidos iônicos com modelos de composição local/contribuição de grupo e estruturas moleculares determinadas via química quântica. Tese de Doutorado. Departamento de Engenharia Química. Universidade Estadual de Campinas, 2009.

SELIG, M.; WEISS, N.; JI Y. Enzymatic saccharification of lignocellulosic biomass. Laboratory Analytical Precedure (LAP), Technical report, NREL, 2008.

STRACKE, M. P. Líquidos iônicos: Síntese, caracterização, utilização como reservatórios moleculares de hidrogênio e aplicação em baterias. Dissertação de Mestrado. Instituto de Química. Universidade Federal do Rio Grande do Sul. 194f. Porto Alegre. 2008.

VAN DYK, J. S.; PLETSCHKE, B. I. A review of lignocellulose bioconversion using enzymatic hydrolysis and synergistic cooperation between enzymes-Factors affecting enzymes, conversion and synergy. Biotechnol. Advances v. 30, p. $1458-1480,2012$

ZAKRZEWSKA, M. E.; BOGEL-LUKASIK, E.; BOGEL-LUKASIK, R. Ionic liquid-mediated formation of 5hydroxymethylfurfural-A promising biomass-derived building block. Chem. Reviews, v. 111 (2), p. 397-417. 2011. 